\title{
Geodiversidade, turismo e educação: a divulgação científica virtual no período de pandemia
}

\author{
Geodiversity, tourism, and education: virtual scientific dissemination in the pandemic period
}

\author{
Raphaela A. de Oliveira Araujo \\ Mestranda pelo Programa de Pós-Graduação em Geografia - PPGEO UNIFAL MG, Brasil \\ raphaela.araujo@sou.unifal-mg.edu.br \\ Gabriel Flora Vieira \\ Mestrando pelo Programa de Pós-Graduação em Geografia - PPGEO UNIFAL MG, Brasil \\ gabriel.flora@sou.unifal-mg.edu.br \\ Paulo Henrique de Souza \\ Professor Dr. do Programa de Pós-Graduação em Geografia - PPGEO UNIFAL MG, Brasil \\ paulohenrique.souza@unifal-mg.edu.br \\ Clibson Alves dos Santos \\ Professor Dr. do Programa de Pós-Graduação em Geografia - PPGEO UNIFAL MG, Brasil \\ clibson.santos@unifal-mg.edu.br
}

\begin{abstract}
Resumo
Os estudos concernentes a Geodiversidade tem sua gênese na década de 1990, tendo a convenção de Malvern como marco conceitual, desde então, os mesmos vêm se consolidado em pesquisas em todo o globo, possibilitando novas interpretações da natureza e dos sistemas ambientais inerentes a vida humana. Este artigo tem por finalidade apresentar uma breve análise sobre os conceitos da Geodiversidade, Geoconservação e Geoturismo, os entendendo como uma tríade para o conhecimento e preservação do meio abiótico. Desta forma, também se busca neste trabalho evidenciar a importância da divulgação geocientífica neste período de pandemia, o qual trouxe a imposição de um novo paradigma para a comunicação e distribuição de informações, se apropriando deste para proporcionar o conhecimento acerca da diversidade abiótica. Ainda neste artigo será também analisado o aparecimento destes termos na educação básica por meio da Base Nacional Comum Curricular, documento que norteia as competências e habilidades a serem desenvolvidas na etapa de ensino. Em consequência à importância empregada à divulgação geocientífica voltada ao Geoturismo, este artigo conta com diversos exemplos de iniciativas pioneiras que buscam explicitar possibilidades de interligação do lazer e o conhecimento científico.
\end{abstract}

Palavras-chave: Educação Geocientífica; Geodiversidade; Currículo escolar; Tecnologias.

\begin{abstract}
The studies concerning Geodiversity have their genesis in the 1990s, with the Malvern Convention as a conceptual framework. Since then, they have been consolidated in research around the globe, enabling new interpretations of nature and environmental systems inherent in human life. This article aims to present a brief analysis of the concepts of Geodiversity, Geoconservation and Geotourism, understanding them as a triad for the knowledge and preservation of the abiotic environment. In this way, this work also highlights the importance of geoscientific dissemination in this pandemic period, which brought the imposition of a new paradigm for communication and distribution of information, appropriating this to provide knowledge about the abiotic diversity. Furthermore, this article will also
\end{abstract}


analyze the appearance of these terms in basic education through the Common National Curricular Base. Thus, this document guides the competencies and skills to be developed at this stage of education. Finally, due to the importance of the geoscientific divulgation focused on Geotourism, this article counts with several examples of pioneer initiatives that seek to explain possibilities of interconnection between leisure and scientific knowledge.

Keywords: Geoscience education; Geodiversity; School curriculum; Technologies.

\section{INTRODUÇÃO}

Um dos principais enfrentamentos e resistências nesse período atípico foi pela continuidade da qualidade de ensino de milhões de alunos que perderam o contato com a escola. Para isso, inúmeros recursos surgiram em busca de encurtar as distâncias entre educadores e alunos, e com eles a exigência de habilidades que antes os profissionais da área não necessitavam. As plataformas de vídeo conferência, mídias sociais, e-mail, entre outras redes, antes muito populares entre os meios corporativos e de entretenimento, agora são tomadas por alunos e professores a passos dificultosos.

O período de reclusão social e aulas remotas tornaram ainda mais complexo o processo de ensino-aprendizagem, se tratando de metodologias onde o processo requer ainda mais autonomia e didática, propostas práticas como a educação ambiental e patrimonial, a problemática é ainda maior. Projetos que antes eram realizados em museus, Geoparques e Unidades de Conservação agora se encontram em sites com roteiros virtuais, plataformas de vídeo ou redes sociais. Apesar da possibilidade de os conteúdos alcançarem lugares que antes não era possível, também nos faz problematizar o acesso dos alunos aos meios virtuais.

Este trabalho nasce a partir de uma breve análise, além de relato de experiências sobre o ensino e divulgação Geocientífica feita por professores, academia e pesquisadores durante a pandemia através da internet. Essa temática foi apresentada na Mesa Redonda "Geografia e os Geopatrimônios físicos e humanos" no evento virtual II COLÓQUIOS GEOGRÁFICOS DO PPGEO UNIFAL-MG "Leituras geográficas sobre o avanço da extrema direita no Brasil: Resistências e Enfrentamentos em tempos de Pandemia”, realizado no dia 27 de julho de 2021 e transmitido pelo Youtube.

Portanto, o seguinte artigo tem como objetivo contribuir para as discussões sobre a divulgação da Geodiversidade formando multiplicadores através da educação Geocientífica, apresentando os principais conceitos utilizados na divulgação da Geodiversidade, discutindo sobre as metodologias de ensino Geocientífica em especial a Educação Ambiental e Educação Patrimonial. Além disso, serão apresentadas propostas de uso da tecnologia e mídias sociais, que apresentaram forte crescimento no período de pandemia e os desafios encontrados pelos educadores ao ter de utilizar tais recursos. 


\section{REVISÃO BIBLIOGRÁFICA}

Ao se tratar de Geodiversidade, outros conceitos precisam ser discutidos para que a temática fique clara. Apesar do termo não estar presente ainda nos currículos escolares, ao se estudar e compreender a temática, é possível observar como este e outros conceitos das Geociências estão fragmentados pelos currículos de Geografia e Ciências dos ensinos fundamental e médio.

Assim, entende-se que a Geodiversidade corresponde às características geológicas (rochas, minerais e fósseis), geomorfológicas (formas de relevo, topografia e processos físicos), hidrológicas e os solos. Inclui o conjunto de ambientes, estruturas e sistemas, contribuindo para as paisagens. É o equivalente abiótico da biodiversidade (GRAY, 2013). Com isso, os componentes da geodiversidade estão associados a valores, que podem ser funcionais, estéticos, lendários, econômicos, ambientais, educativos e/ou científicos, entre outros, vinculam-se às funções eco e Geossistêmica, e podem proporcionar benefícios relacionados a elementos, feições e sistemas terrestres (GRAY, 2013). Os benefícios do reconhecimento da Geodiversidade e sua conservação têm sido cada vez mais reconhecidos em diversas instâncias uma vez que a sua permanência demonstra grandes benefícios e riquezas, conforme afirma Mansur (2018):

\footnotetext{
Tais benefícios podem ser o contato direto com o solo e a rocha em trilhas, a contemplação de paisagens geomorfológicas em mirantes e a recreação em cursos hídricos e em praias marinhas. Isso torna importante a conservação desses ambientes, no desenvolvimento e na manutenção de tais atividades, que se traduzem em lazer, educação, eco e geoturismo. (MANSUR, 2018. p. 220)
}

Para mudar esse cenário, a área tem sido cada vez mais explorada nas pesquisas acadêmicas com o objetivo de alcançar o grande público, pois de fato ainda há muitas questões a serem descobertas e discutidas, destarte, termo geodiversidade já existe há mais de 15 anos, porém para se ter uma ideia, o primeiro livro dedicado ao tema somente foi publicado em 2004 e corresponde ao Geodiversity: valuing and conserving abiotic nature, de Murray Gray (Professor do Departamento de Geografia da Universidade de Londres, Reino Unido) (NASCIMENTO et. al, 2008).

Em conjunto aos estudos sobre a Geodiversidade, o conceito de patrimônio geológico, que é representado pelo conjunto de sítios geológicos (ou geossítios), e esses são paralelos, contudo, não se deve encarar o patrimônio geológico como sinônimo de geodiversidade Nascimento et. al (2008). Sobre esta semelhança os autores orientam que:

A geodiversidade, de forma simples, consiste em toda a variedade de minerais, rochas, fósseis e paisagens que ocorre no Planeta Terra. Já o patrimônio geológico é apenas uma pequena parcela da geodiversidade apresentando características especiais e que, por conseguinte, deve ser conservado. (NASCIMENTO et. al, 2008 p. 10)

O Patrimônio Geológico, no entanto, na medida em que a comunidade de geociências reconhece, de forma explícita, a necessidade de garantir a salvaguarda dos elementos notáveis do 
patrimônio geológico, esse quadro tende a alterar-se, com adoção de medidas específicas de geoconservação em todas as partes do mundo (NASCIMENTO et. al, 2008). Raciocinando neste contexto, Mansur (2018) afirma que a noção de Geodiversidade suplementa a noção corrente de biodiversidade como mais um elemento do meio natural a ser avaliado na caracterização de um dado território, seja para protegê-lo, seja para ordenar sua ocupação ou uso.

Outro conceito necessário para a compreensão da Geodiversidade e que vem ganhando força nos últimos anos tanto dentro das discussões acadêmicas quanto em sua prática e legislação é o Geoturismo. Segundo Hose (2012) o Geoturismo pode ser definido como uma forma de turismo sustentável que objetiva também a valorização da geodiversidade "in situ" e "ex situ". Busca-se, a partir da disponibilização de interpretação ambiental e outros serviços, sensibilizar o público visitante sobre a importância da Geoconservação, de forma a beneficiar social e economicamente as populações locais.

A prática do Geoturismo vai além do uso recreativo e de lazer, abrangendo de forma importante estudantes em trabalho de campo e comunidades de entorno a áreas de interesse geológico. Os valores educacionais e científicos são discutidos amplamente por grandes pesquisadores como Brilha (2005), Mansur (2009, 2013 e 2018), Guerra (2016), Nascimento (2008), Moreira (2014), Ruchkys (2008), entre muitos outra de tamanha relevância para o avanço do tema. Além disso, a presença de pontos de valores Geoturísticos, é de grande importância para desenvolvimento socioeconômico local.

Portanto, é necessário compreender que a prática do Geoturismo, mesmo por fins de estudos e pesquisa causam certo impacto, sendo necessário seguir os protocolos de Geoconservação impostos pelo lugar visitado. Em resumo a Geoconservação não pretende proteger toda a geodiversidade, mas sim o patrimônio geológico, mantendo os Geossítios de modo a permitir o seu uso, seja científico, educativo, turístico, entre outros (NASCIMENTO et. al, 2008. p. 22). Sendo assim, conforme aponta Moreira (2014):

Independentemente do estado ou país em que é realizado, o geoturismo pode proporcionar diversos impactos, tanto positivos, quanto negativos. Sabe-se que qualquer atividade humana produz impactos no ambiente em que é realizada. $O$ turismo não foge a essa regra, causando impactos que podem abranger efeitos econômicos, ambientais e socioculturais. (MOREIRA, 2014. p. 32)

Uma das principais formas de divulgação e difusão desses conceitos e temática em geral, se encontram inclusos no ensino das Geociências. Já compreendida a noção de Geodiversidade, observase em Toledo (2005 apud Silva 2018, p. 25) a seguinte definição de ensino de Geociências:

O termo Geociências é aqui utilizado como o conjunto das Ciências que estudam a Terra, seus vários compartimentos, materiais e processos e, principalmente, sua evolução histórica, desde a origem do Sistema Solar, e até mesmo a comparação com outros corpos do sistema solar ou fora dele. Na classificação usual em agências financiadoras de pesquisas, Geociências incluem Geologia, Geofísica, Meteorologia, Geodésia e Geografia Física. Em 
nosso contexto, devemos ainda considerar a Oceanografia, além de outras ora consideradas Ciências independentes, ora consideradas ramos da Geologia ou da Geografia Física, que contribuem para a compreensão do Sistema Terra. (TOLEDO, 2005 p. 32 apud Silva 2018, p. 25).

A partir disso, tem-se a Geodiversidade sendo divulgada através da educação de instrução de turistas a visitantes de áreas protegidas e através do ambiente escolar. Esse ensino se dá por meios formais e informais, dentro das dependências da escola ou fora dela. Se tratando de um contexto pandêmico, as abordagens metodológicas passaram por adaptações. Tais práticas de ensino serão melhor discutidas a seguir.

\section{A EDUCAÇÃO GEOCIENTÍFICA - O USO DOS RECURSOS ONLINE DURANTE A PANDEMIA}

As recentes transformações dos currículos e a configuração do novo ensino médio fizeram com que o ensino de geografia e geociências em geral perdesse sua força e a previsão é que gradualmente cause desinteresse nos alunos. Outro fator alarmante e que deve ser observado é a dispersão dos conhecimentos geocientíficos nos componentes curriculares da BNCC o que compromete a aprendizagem e, consequentemente, a alfabetização geocientífica na educação básica nacional. Ao se pesquisar o termo "Geodiversidade" ou conceitos afins como "Geoconservação", "Geoparque" ou "Geoturismo" pelos currículos escolares brasileiros não se encontra, apesar de em alguns eventos científicos e palestras recentes, profissionais da área afirmam já encontrar alguns desses termos em livros didáticos produzidos a partir de 2019.

O conhecimento é significativo por definição. É o produto significativo de um processo psicológico cognitivo ("saber") que envolve a interação entre ideias "logicamente" (culturalmente) significativas, ideias anteriores ("ancoradas") relevantes da estrutura cognitiva particular do aprendiz (ou estrutura dos conhecimentos deste) e o "mecanismo" mental do mesmo para aprender de forma significativa ou para adquirir e reter conhecimentos. (AUSUBEL, 2003 p.4). Portanto, as metodologias e práticas de ensino recentes buscam a criação de uma significação entre aluno e conhecimento.

\footnotetext{
A problematização é uma metodologia que pode auxiliar os estudantes no ensino e aprendizagem. Essa metodologia sugere que os estudantes procurem alternativas para solucionar problemas que partam de conteúdos formais de sala de aula para o seu cotidiano ou o contrário. Essa metodologia estimula os conhecimentos e habilidades dos alunos, quando são incentivados a resolver os problemas e conseguem relacionar a teoria na prática: essas resoluções geram discussões relevantes para construção de conhecimentos. (AZEVEDO, 2006 apud SILVA E GUIMARÃES, 2016 p. 9)
}

Ao se discutir os desafios e possibilidades do ensino das Geociências deve-se levar em consideração o nível de dificuldade de certos conteúdos das áreas de Geologia e Geomorfologia, 
portanto, necessita-se uma abordagem didática e simplificado principalmente se tratando de meios de ensino remoto. Vale ressaltar nessa figura o fato de que alfabetização biológica ou geocientífica são caminhos metodológicos característicos das áreas específicas de conhecimento para o processo de formação de um cidadão alfabetizado cientificamente, que possui capacidades e competências, possibilitando sua participação no processo de decisões cotidianas (SILVA, 2018. p. 38). A forma de abordagem e os recursos didáticos variam muito com os anos de escolaridade, é preciso preparo e pesquisa.

Objetiva-se com as metodologias de ensino e divulgação da Geodiversidade, e conscientizar sobre a necessidade de sua proteção. De acordo com Queiroz e Quintanilha (2020) esse ensino deve articular os objetivos da conservação ambiental com os objetivos da transformação social, destacando a importância da implementação de ações que capacitem os atores (guardas, gestores, voluntários. Pesquisadores, alunos, entre outros) a intervir, sempre que necessário, nesses espaços naturais, para que os objetivos surgidos a partir dessa articulação sejam alcançados, e as transformações efetivas.

Dessa forma, as Unidades de Conservação podem ser utilizadas para a realização de atividades geoeducativas, pois, também segundo a UFC (2007), a geoeducação pode ser realizada fora das salas de aula: A geoeducação incorpora a necessidade por desenvolver projetos de intercâmbios entre práticas sócio pedagógicas, internas e externas à educação escolar. Parte do pressuposto de que o espaço geográfico (em suas manifestações materiais e imaginárias) também educa; até mais efetivamente do que os conhecimentos curriculares específicos (MOREIRA, 2014. P. 73)

Um exemplo de prática para a multiplicação dos conhecimentos sobre a Geodiversidade são as Oficinas Pedagógicas. Estas também priorizam a formação autônoma do conhecimento, e pode ser aplicada na formação docente ou para a educação básica. Estudiosos da aplicação de oficinas pedagógicas na formação de alunos e professores concordam que essa é uma forma de se contrapor ao ensino memorístico, no qual há um sujeito submetido ao saber do outro, não desenvolvendo sua autonomia, sua autoria em relação à produção e problematização do conhecimento. As oficinas pedagógicas colocam os seus sujeitos como parceiros em suas aprendizagens. (FRIGÉRIO, 2018 p. 54)

Além de promover a autoria, a autoridade e a autonomia do aluno na produção de conhecimento em aulas-oficinas, alarga a importância do outro na aprendizagem como processo coletivo, esvaziado de solidão, em inaugurações sucessivas de solidariedade. (FRIGÉRIO, 2018 p. 89). No esquema abaixo pode-se entender como a formação de multiplicadores a partir do ambiente escolar (Figura 1). 


\section{Formação docente}

\section{Alunos}

\section{Comunidade}

Figura 1 - Esquema da formação de multiplicadores para a conservação do Patrimônio Geológico.

Fonte: Os autores.

Durante apresentação oral no evento II Colóquios Geográficos (PPGEO/UNIFAL-MG), exemplificou-se possibilidades do uso de aplicativos para o ensino da Geodiversidade durante o período de atividades remotas e também presenciais. Os aplicativos demonstram diversas possibilidades de aplicação didática e facilidade de uso para até mesmo séries escolares iniciais. Entre os diversos exemplos disponíveis destacamos 3 aplicativos que tratam da temática da Geodiversidade (Tabela 1).

Tabela 1: Exemplos de possibilidades do uso de aplicativos e eventos científicos no ensino da Geodiversidade.

\begin{tabular}{|c|c|}
\hline Aplicativos & Funcionalidade aplicada ao Geoturismo \\
\hline Wickloc & $\begin{array}{l}\text { Este aplicativo dispõe um caráter global, possuindo milhões de trilhas em todo o globo. } \\
\text { Essas trilhas possuem sugestões de atividades a serem desenvolvidas em diferentes modelos } \\
\text { como corridas, caminhadas, caiaque etc. Dentre suas funcionalidades estão a possibilidade } \\
\text { de gravar as rotas percorridas em mapa, retirar fotos para lembrança e mapas topográficos } \\
\text { disponíveis off-line. Fonte: Google PlayStore. }\end{array}$ \\
\hline Geocaching & $\begin{array}{l}\text { Este app possui um caráter global, possuindo infraestrutura de desenvolvimento em mais de } \\
185 \text { países. O aplicativo consiste em milhões de recipientes escondidos conhecidos como } \\
\text { "geocaches" espalhados em trilhas para auxiliar no percorrer das trilhas. Ao localizar essas } \\
\text { caixas mais tradicionais, o participante pode entrar em comunicação com os demais e obter } \\
\text { por meio deles dicas para as próximas caixas escondidas na referida trilha, tornando o } \\
\text { percurso atrativo e mais fácil. Fonte: Google PlayStore. }\end{array}$ \\
\hline $\begin{array}{l}\text { Guia de } \\
\text { Minerais }\end{array}$ & $\begin{array}{l}\text { Este guia de minerais possui características incríveis que possibilitam o aprendizado, } \\
\text { possuindo mais de } 4000 \text { definições, características ou termos empregados em mineralogia. } \\
\text { Este app é ideal tanto para profissionais quanto estudantes. Suas possibilidades são } \\
\text { inúmeras, dentre elas a pesquisa avançada, que auxilia no preenchimento da pesquisa, a } \\
\text { pesquisa por voz, diversas ilustrações do que se pesquisa e a opção de uso off-line. Fonte: } \\
\text { Google PlayStore. }\end{array}$ \\
\hline
\end{tabular}

Além disso, discutiu-se no colóquio o benefício de eventos científicos online para a disseminação, difusão e divulgação da Geodiversidade, somado que essa modalidade de eventos possibilita reunir pesquisadores, educadores e demais profissionais da área de diversas partes do país e do mundo, como pode ser visto nos exemplos dispostos na tabela abaixo (Tabela 2). 
Tabela 2: Exemplos de possibilidades do uso de aplicativos e eventos científicos no ensino da Geodiversidade.

\begin{tabular}{|c|c|c|c|}
\hline $\begin{array}{c}\text { Eventos online e PodCasts } \\
(2020-2021)\end{array}$ & Plataforma & Endereço Eletrônico & $\begin{array}{c}\text { Acessos até o } \\
\text { presente momento }\end{array}$ \\
\hline $\begin{array}{c}\text { Projeto Café Geológico - } \\
\text { CPRM }\end{array}$ & Youtube & $\begin{array}{c}\text { https://www.youtube.com/c/TVC } \\
\text { PRM/featured }\end{array}$ & $\begin{array}{l}\text { Live mais acessada: } \\
1626 \text { visualizações. }\end{array}$ \\
\hline $\begin{array}{l}\text { Quartas no Lagesolos - } \\
\text { UFRJ }\end{array}$ & Youtube & $\begin{array}{c}\text { https://www.youtube.com/channel } \\
\text { /UCY2bjGbP3HnbRUHdKk1j1U } \\
\text { Q }\end{array}$ & $\begin{array}{l}\text { Inscritos no canal: } \\
2,02 \text { mil e Live mais } \\
\text { assistida: } 2 \text { mil } \\
\text { visualizações. }\end{array}$ \\
\hline $\begin{array}{c}\text { II Workshop Projeto } \\
\text { Geoparque Costões e } \\
\text { Lagunas do Rio de Janeiro }\end{array}$ & Youtube & $\begin{array}{l}\text { https://www.youtube.com/c/geopa } \\
\text { rquecostoeselagunasdorj }\end{array}$ & $\begin{array}{c}\text { Inscritos no } \\
\text { canal: } 565 . \\
\text { Video mais assistido: } \\
936 \text { visualizações }\end{array}$ \\
\hline $\begin{array}{l}\text { I Seminário de Educação } \\
\text { Patrimonial - Geoparque } \\
\text { Caminhos dos Cânions do } \\
\text { Sul }\end{array}$ & Youtube & $\begin{array}{c}\text { https://doity.com.br/seminariocani } \\
\text { onsdosul }\end{array}$ & $\begin{array}{l}\text { Inscritos no canal: } \\
525 \\
\text { Live mais assistida: } \\
308 \text { visualizações }\end{array}$ \\
\hline $\begin{array}{l}\text { Dialogando com o } \\
\text { Geoparque Seridó }\end{array}$ & Youtube & $\begin{array}{l}\text { https://www.youtube.com/channel } \\
\text { /UCGVy6DaSaf23u-IenVxx42Q }\end{array}$ & $\begin{array}{l}\text { Inscritos no canal: } \\
1,18 \text { mil. } \\
\text { Live mais assistida: } \\
6,1 \text { mil visualizações. }\end{array}$ \\
\hline $\begin{array}{c}\text { TerraVersa - Projeto } \\
\text { Geoparque Costões e } \\
\text { Lagunas do Rio de Janeiro - } \\
\text { CNPq - Grupo de Pesquisa } \\
\text { Geodiversidade e Memória } \\
\text { da Terra } \\
\end{array}$ & Spotify & $\begin{array}{l}\text { Aplicativo disponível em todos os } \\
\text { sistemas operacionais de } \\
\text { smartphones }\end{array}$ & $\begin{array}{l}\text { Não disponível na } \\
\text { plataforma }\end{array}$ \\
\hline $\begin{array}{c}\text { Episódio } 1 \text { - GEOCAST - } \\
\text { Conhecendo o Geoparque } \\
\text { Caminhos dos Cânions do } \\
\text { Sul }\end{array}$ & Spotify & $\begin{array}{c}\text { https://open.spotify.com/episode/ } \\
\text { 2g2hRxUSKrW7OkkRpsYSaC?si } \\
\text { =xyFxqvAXT9Sji5p1CWYDeQ\& } \\
\text { dl_branch=1 }\end{array}$ & $\begin{array}{l}\text { Não disponível na } \\
\text { plataforma }\end{array}$ \\
\hline $\begin{array}{c}\text { Episódio } 2 \text { - GEOCAST - } \\
\text { Arqueologia do território } \\
\text { Geoparque }\end{array}$ & Spotify & $\begin{array}{c}\text { https://open.spotify.com/episode/ } \\
\text { 40QNXOvLnv10cMlujamO2H?si } \\
=\text { uduIZLpGSXmw- } \\
\text { XoRzoUemg\&dl_branch=1 }\end{array}$ & - \\
\hline
\end{tabular}

Elaboração: os autores.

Esclarece-se que o objetivo aqui não foi realizar um levantamento exaustivo das mídias disponíveis, mas sim uma exemplificação das potencialidades disponíveis para uso remoto, que podem ser acessadas de forma gratuita em plataforma digitais como o Youtube e Spotify, que disponibilizam vídeos e podcasts, respectivamente.

\section{METODOLOGIA E ACESSO À INFORMAÇÃO}

A partir do surgimento de recursos didáticos remotos, as metodologias de ensino passaram por adaptações para se encaixar no mundo virtual. A utilização de meios formais e informais de ensino como por exemplo as redes sociais e plataformas de vídeo conferência e exigiram de alunos e educadores maior sensibilidade. Veículos de comunicação dinâmicos requerem linguagem e relações dinâmicas. 
As metodologias comumente usadas no ensino da Geodiversidade propõem a construção de um conhecimento autônomo e crítico, capaz de despertar no aluno a necessidade de participação e identificação com o Patrimônio Geológico. Ter em mãos este tipo de recurso didático é de grande utilidade para quem trabalha em museus, principalmente com o público escolar (professores e alunos) e públicos especiais, pois melhor esclarece e fundamenta o trabalho de "conhecimento, apropriação e valorização de diferentes culturas, em diferentes lugares e épocas (ELAZARI, 1999 p. 292). Podemos compreender a importância da aplicação de metodologias para o ensino de Geodiversidade a partir de Nascimento et. al (2008):

Esse processo é muito útil para a preservação do patrimônio geológico por dois principais
motivos. O primeiro deles é o investimento na sua salvaguarda. Uma vez que a população
local passa a se identificar e a compreender a importância daqueles elementos da
geodiversidade como patrimônio, ela irá desejar e incentivar a sua proteção. Na ausência do
poder público, depredações e vandalismos poderão ser coibidos pela população local. O
segundo motivo é o compromisso social que todos os cientistas devem ter. Com a proposta
da educação patrimonial há um retorno para a comunidade, transmitindo o conhecimento que
foi construído através dos Geossítios (Souza 2006; Castro \& Machado2011). (Apud
NASCIMENTO et. al, 2008 p. 152)

A primeira metodologia mais utilizada na diretriz escolar e fora dela é a Educação Ambiental. Quanto a ela entende-se que o papel da educação ambiental crítica como um objeto catalisador para mudanças de hábitos sociais, pode ser aproveitado através da interpretação do patrimônio, seja imaterial ou ligado aos aspectos referentes à biodiversidade e geodiversidade. Esta tem sido utilizada em diversos projetos e estudos, o que demonstra o seu potencial para o desenvolvimento sustentável das regiões. (BAPTISTA; MOREIRA, 2020. p. 6)

A EA (Educação Ambiental) é utilizada não somente no ensino sobre o ambientem abiótico o qual está inserido a Geodiversidade, mas principalmente sobre o ambiente biótico, onde neste possui a maior propagação. Esta metodologia tem a viabilidade de ensino desde a sala de aula para alunos do ensino básico, a aplicações em museus e pontos turísticos. Tal não se apresenta engessada, sendo capaz de se adaptar para promover a preservação de pontos de interesse. Neste sentido entende-se que o processo de educação pode ser implementado em conjunto com a interpretação do patrimônio, reforçando a dialética entre preservação e uso racional de atrativos. Acredita-se ainda, que ao conhecer melhor sobre as fragilidades e a história do patrimônio, a percepção e as atitudes de visitantes em futuros passeios poderão ser norteada pelo conhecimento adquirido em experiências prévias, formando assim, uma identidade sustentável. (BAPTISTA; MOREIRA, 2020. p. 3)

Além disso, Nascimento et. al (2008) orientam que, para tanto, deve-se utilizar a educação ambiental como aliada na orientação sobre a conservação e utilização racional dos recursos turísticos naturais. Assim, o repasse do conhecimento deve ser facilitado, para que cumpra a sua função e possa 
alavancar processos participativos que favoreçam a Geoconservação (NASCIMENTO et. al, 2008 p. 72). E ainda reafirmam que:

\begin{abstract}
Em relação à educação ambiental e voltando-se para os aspectos da geodiversidade, é necessário resgatar e repassar ainda mais as características geológicas e geomorfológicas das Áreas Protegidas, compartilhando conhecimentos sobre a história geológica, sua importância, recursos e fragilidade do ambiente. Favorecendo a aprendizagem em parceria e a reflexão sobre atitudes e procedimentos diante das questões ambientais, contribui-se para a adoção de práticas pedagógicas e interpretativas. (CRIVELARO, 2001 apud NASCIMENTO et. al, 2008 p. 72.)
\end{abstract}

A segunda metodologia utilizando no ensino da Geodiversidade, apesar de ainda recente no meio das Geociências é a Educação Patrimonial. Esta ainda é muito utilizada para ensino e difusão de patrimônio cultural e histórico, porém recentemente, em meio a adaptações, tem-se adentrado no ensino de patrimônio natural, especificamente o geológico.

Tendo em vista os valores científicos, turísticos e econômicos de pontos de interesse geológico, tem-se confirmado cada vez mais a necessidade de sua proteção e desenvolvimento sustentável. Nesse sentido, a educação patrimonial tem um caráter transformador e emancipatório. A relação entre educação, cultura e política que a sustenta condiz com as ideias difundidas pelo educador brasileiro Paulo Freire. Por essa razão, é frequente a adoção da perspectiva freiriana em artigos, livros, ações e projetos de educação patrimonial no país (BEZERRA, 2020).

Segundo Magalhães et. tal (2009), refletindo sobre a origem epistemológica da palavra patrimônio, derivado do latim pater, significa tudo aquilo que um pai deixava para seu filho. Contudo, a partir da Rev. Francesa no século XVIII, esse termo ampliou-se para agrupar um sentido coletivo, ou seja, representando aquilo que os ancestrais de uma determinada sociedade deixaram para seus contemporâneos. É preciso perceber que a elevação de algo como patrimônio perpassa por uma seleção contemporânea. Ou seja, os indivíduos do passado não deixaram deliberadamente aquele objeto, saber, construção, ou expressão, como patrimônio. "É um recorte e uma identificação do presente" (MAGALHÃES et. al, 2009).

O patrimônio adquire assim uma lógica includente, atuando na resolução do grande problema a formação do Estado no século XVIII, ou seja, a inclusão de todos na esfera da administração estatal, garantindo a lealdade dos cidadãos ao sistema, colocando-se acima dos conflitos de classes e dos sociais. (MAGALHÃES et. tal, 2009. p. 34)

Tendo em vista tal conceituação, o Patrimônio Geológico também se mostra como herança histórica e cultural de valor a ser conservado. Entende-se, portanto, que a educação patrimonial busca legar crianças e adultos a um processo ativo de conhecimento crítico, apropriação consciente e consequente valorização de sua herança cultural, o que possibilita o fortalecimento dos sentimentos de identidade e cidadania (SANTOS; PACHECO, 2009 p. 149). Além disso: 
A educação patrimonial foi implantada no Brasil na década de 1980 por Maria de Lourdes Parreiras Horta, do Museu Imperial do Rio de Janeiro. Sua metodologia tornou-se uma alternativa de alfabetização cultural. Esta promove uma transformação na maneira de tratar a cultura e busca revisão e aprimoramento nas formas de devolução do conhecimento científico para o público leigo. O cidadão precisa compreender sua importância no processo sociocultural-ambiental no qual está inserido e vislumbrar uma mudança positiva no seu relacionamento com o patrimônio ambiental-cultural. (SANTOS; PACHECO, 2009 p. 149.)

Assim, a Educação Patrimonial surge como uma dimensão da educação cujo principal objetivo é promover a sensibilização sobre a importância do patrimônio, e de sua preservação, na formação de sujeitos e de sua própria história, que atuem na reivindicação de seus direitos coletivos e no fortalecimento de sua cidadania (BEZERRA, 2020). Portanto, a educação patrimonial é uma ação que visa à conscientização das comunidades acerca da importância da criação, valorização e preservação do patrimônio arqueológico local. (SANTOS; PACHECO, 2009 p. 151)

Do mesmo modo, a Educação Patrimonial permite ao educador o uso de atividades relacionadas a realidade dos alunos, de modo a trazer significado para que o aluno entenda a necessidade da preservação do patrimônio e que este é parte de si. Isso é possível porque a educação patrimonial é materializada por meio do estudo de objetos comunitários como estratégia de aprendizagem do contexto sociocultural/ambiental. Toda ação educativa deve ser elaborada tendo em vista as necessidades das comunidades envolvidas (SANTOS; PACHECO, 2009 p. 150).

Ou seja, deve-se garantir que os patrimônios já consolidados adquiram novos olhares, e que estes sejam respeitados e levados em consideração, além do fato de que novos patrimônios possam ser identificados. Sabemos, no entanto, da dificuldade de garantir esta diversidade de olhares e de possibilidades, por significar espaço de expressão identitária, apontando suas contradições, ou jogos de interesses e os conflitos decorrentes. Daí a necessidade de uma educação patrimonial que leve não a informação, mas à reflexão, ao questionamento, ao contraditório e que aproxime as comunidades nos processos de tomadas de decisões. (MAGALHÃES et. al., 2009. p. 47)

Conseguinte, acredita-se que somente através da inclusão da comunidade local em projetos de educação patrimonial e Geoturismo (com a instalação de museus, parques, centros de pesquisa e outras formas de geração de trabalho e renda), a conservação do patrimônio geológico poderá ser concretizada em um país com as dimensões e problemas sociais do tamanho do Brasil (PONCIANO et. al, 2011 Apud MANSUR et. al, 2013 p. 153). No período anterior à reclusão social, Museus, Geoparques e outras instituições realizavam eventos em suas sedes (as turmas iam até o local em trabalho de campo) ou nas próprias escolas de forma a aproximar e apresentar aos alunos elementos da Geodiversidade e artefatos patrimoniais.

Entretanto, como aplicar uma metodologia que requer o uso da prática durante o período de ensino remoto? Uma vez que grande parte dos alunos brasileiros não têm acesso à internet ou uma conexão instável e de má qualidade. A questão é que dentro das limitações de sinais de abandono Estatal, os educadores de todo país de reinventaram para levar o conhecimento aos alunos que conseguem ter acesso mesmo em meio as dificuldades. 
Por outro lado, o fenômeno da Internet oferece uma interessante oportunidade para verificação das diretrizes de desenvolvimento para o futuro. O incentivo ao avanço tecnológico talvez venha a ressaltar a desigualdade do acesso à informação. A importância de a Educação Patrimonial ser construtivista é permitir que os alunos construam seus conhecimentos após a troca e instrução dos seus educadores, o que mesmo nesse período de reclusão ainda é possível. A educação patrimonial transformadora possui caráter político, visando a formação de pessoas capazes de (re) conhecer sua própria história cultural, deixando de ser espectador, como na proposta tradicional, para tornar-se sujeito, valorizando a busca de novos saberes e conhecimentos, provocando conflitos de versões (MAGALHÃES et al., 2009. p. 52)

\section{PROPOSTA PEDAGÓGICA ATRAVÉS DE MÍDIAS SOCIAIS - RELATO DE EXPERIÊNCIA SOBRE A PERFIL NO INSTAGRAM "GEOPLANOS"}

Além das aspirações pessoais e profissionais, em virtude de tempos obscuros quando falamos de informação clara e baseada em fatos, a conta Geoplanos foi criado na rede social Instagram com o objetivo de disponibilizar recursos que auxiliem na educação geocientificamente de forma atrativa e interativa. A página no Instagram foi criada pela pesquisadora e professora de Geografia Raphaela Araujo e é uma proposta pedagógica que apresenta pontos turísticos e belas paisagens chamadas landscapes ${ }^{1}$ juntamente com a informação geográfica, geológica e geomorfológica de lugares muito conhecidos e nem tão famosos. Junto a isso a proposta também aborda conceitualmente algumas temáticas sobre os seguimentos de turismo de aventura em geral como Ecoturismo e Geoturismo.

Numa abordagem educativa, para se apresentar conteúdo científico em redes sociais, um primeiro desafio é ao mesmo tempo entender como se trabalhar nos meios de uma plataforma digital, além de estudar e compreender as estruturas da plataforma desejada, a princípio, é preciso se ter bem delimitado o público-alvo por idades, nível de escolaridade ou instituições. Porém, mesmo com o interesse por uma faixa, é bom deixar claro como é difícil prever o alcance dado pelos algoritmos da plataforma e que nem sempre o público desejado será atingido.

Para a criadora da conta Geoplanos, vinda de uma linguagem acadêmica normativa, o segundo grande desafio foi a adaptação da linguagem técnica dos conteúdos propostos para a linguagem informal da internet sem que esta perca a qualidade de informação dos conteúdos. São necessárias inúmeras tentativas e roupagens desde design à tipo de fonte que chame atenção e instrua ao mesmo tempo. É quase inevitável que um conteúdo perca sua qualidade em um vídeo de apenas 15 ou 30 segundos, mas se este não for exposto dessa forma, é provável que não será visto.

\footnotetext{
${ }^{1} \mathrm{https}: / /$ educalingo.com/pt/dic-en/landscape
} 
O público-alvo pode ser alcançado com o tipo de conteúdo, uso de hashtags, mas o principal para obter visibilidade nesse meio é entrar nas "trends" do momento. Trends ${ }^{2}$ são basicamente modas, ou tipos de vídeos que utilizam as músicas que estão "em alta” e o produtor de conteúdo deve adaptar a sua temática ao tipo de vídeo mais visualizado naquele momento. Geralmente trends duram por uma semana ou poucos dias, portanto, é necessário sempre estar atendo aos assuntos mais comentados ou aos tipos de vídeos mais vistos. Na maioria das vezes é desafiador adaptar um conteúdo educativos nas trends, muitas vezes pelo tipo e tradução das músicas, e por eticamente não ser adequado.

Porém, se o conteúdo não se adaptar ao que os usuários da plataforma consomem, o alcance não será tão satisfatório se mantendo apenas ao nicho de outros pesquisadores e educadores, afirmando por experiência própria. Outro grande desafio, sair do nicho e procurar atingir públicos diversos.

Além de todo um estudo sobre redes sociais e como a entrega do conteúdo para os usuários funciona, educador precisa se expor enquanto profissional, muitas vezes em vídeo, pois uma apresentação humanizada e mais direta é mais apreciada que apenas palavras em um fundo colorido. Ademais considero interesse mostrar que por trás da ciência há cientistas reais, e educadores com interesse de democratizar o conhecimento com as ferramentas que temos acesso.

Outra pauta que deve ser levantada é que o clichê quantidade não é qualidade. Um maior número de seguidores não garante maior interação e interesse pelo conteúdo. Claro que o ideal é uma grande visibilidade para as Geociências, porém os seguidores mais interessados e mais assíduos a aprender e interagir são o que de fato movem uma publicação, além de serem os que mais divulgam e compartilham as postagens.

Entre as diversas publicações, procurou-se abordam em forma de lives de assuntos relacionados a geodiversidade, discutidos a partir da apresentação de estudos de casos (Figura 2).

\footnotetext{
${ }^{2} \mathrm{https}$ ://educalingo.com/pt/dic-en/trend
} 


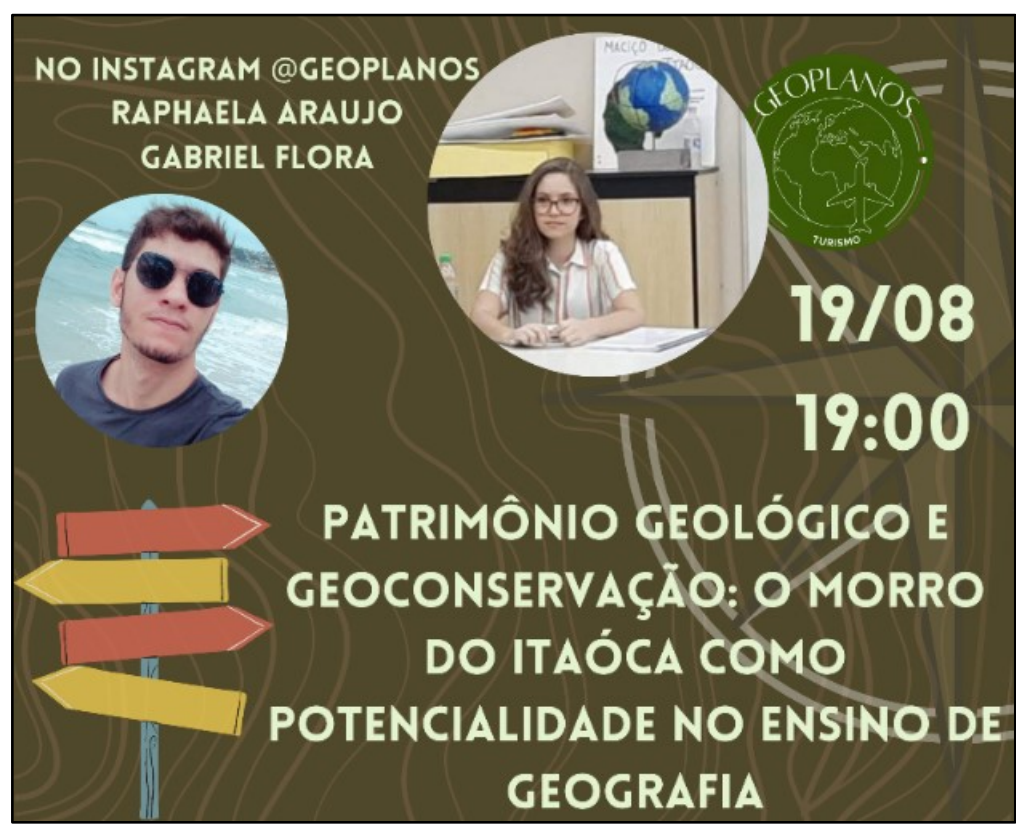

Figura 2 - Divulgação de Live.

Autoria: Criado por Raphaela Araújo - Post no Instagram Geoplanos, 2021.

Os posts também apresentam de forma lúdica, mas ao mesmo técnica conceitos científicos de rotinas comuns para aqueles que de alguma forma realizam atividades ao livre, como por exemplo a prática do turismo de aventura (Figura 3).

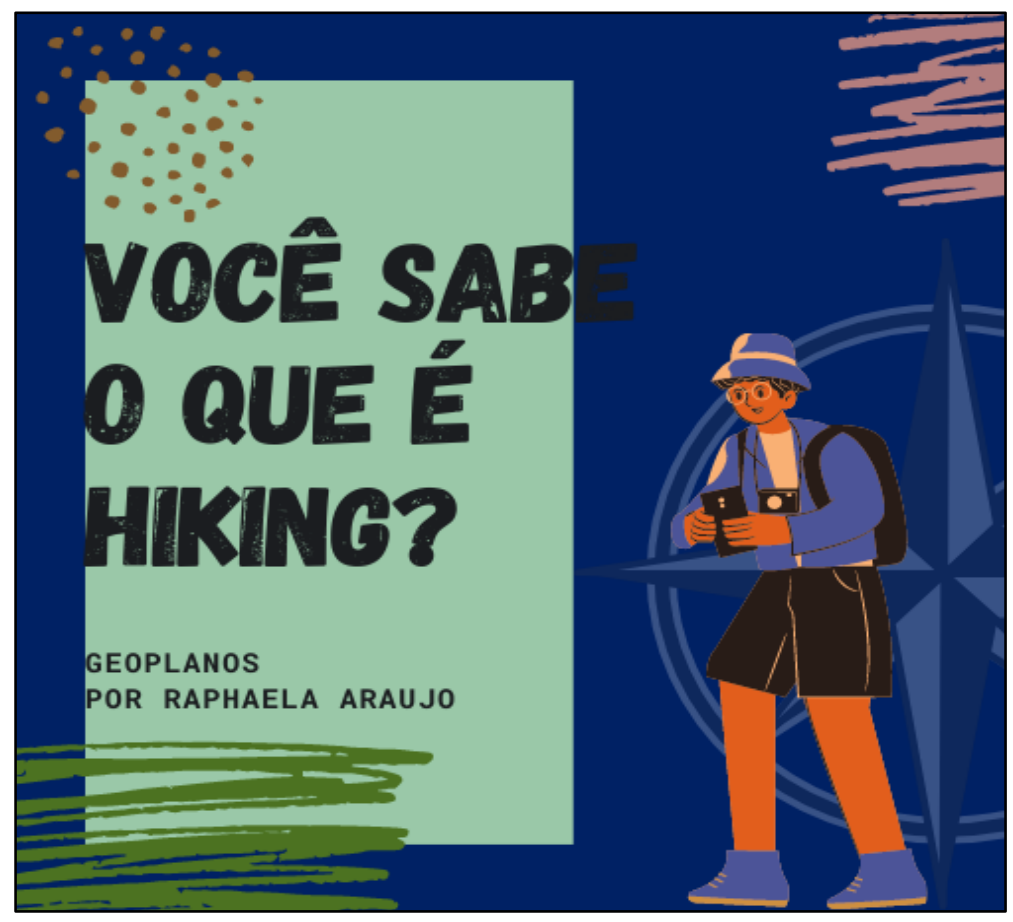

Figura 3 - Postagem de conteúdo sobre prática de turismo de aventura. Autoria: Criado por Raphaela Araújo - Post no Instagram Geoplanos, 2021.

Outra abordagem importante são posts que abordem temas gerais relacionados a valorização do patrimônio geocientífico brasileiro, como a listagem dos geoparques brasileiros, considerando o oficialmente reconhecido pela UNESCO (GeoPark Araripe), como as propostas de projetos 
aprovadas em território nacional e que são extremamente relevantes como patrimônio natural brasileiro (Figura 4).

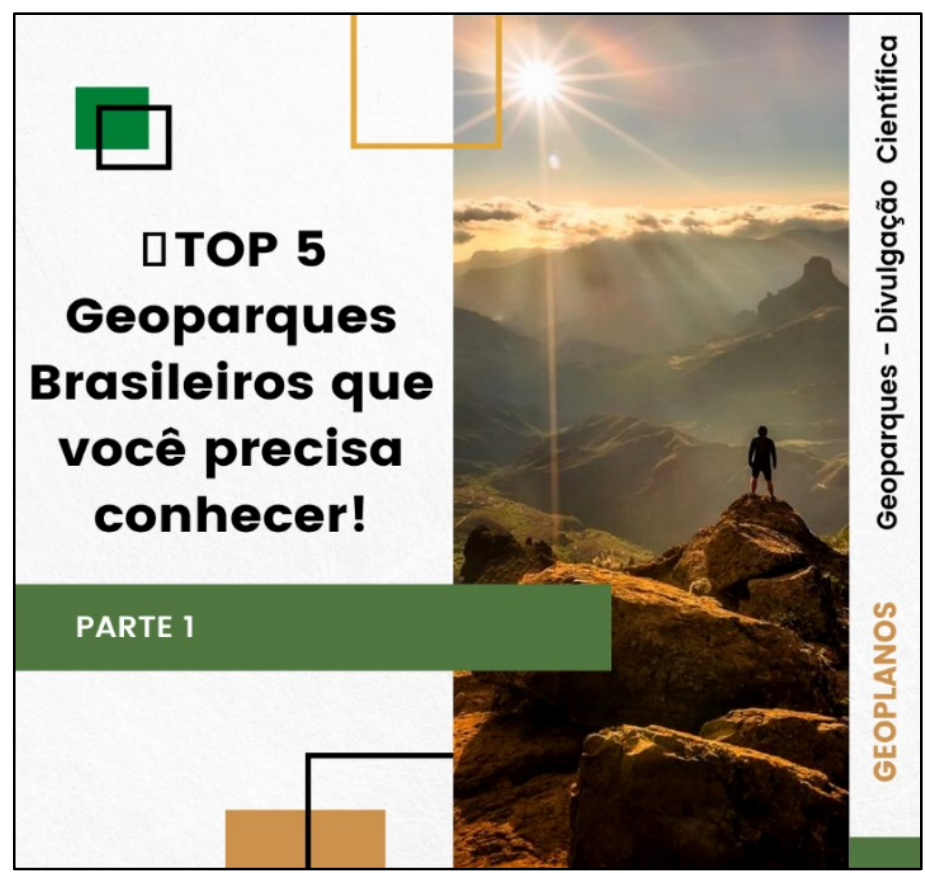

Figura 4 - Postagem sobre atrativos de Geoparques brasileiros. Autoria: Criado por Raphaela Araújo - Post no Instagram Geoplanos, 2021.

Até o momento, foi possível produzir os seguintes tipos de conteúdo:

- $\quad$ Transmissão ao vivo - Lives com pesquisadores convidados;

- Indicações de livros;

- Indicação de Filmes, séries e documentários;

- Enquetes e quis para testar conhecimentos;

- $\quad$ Top 5 geoparques e geossítios;

- Série "Para que serve?";

- $\quad$ Série "Você sabe o que é?";

- Vídeos de Humor;

- Indicações de cursos gratuitos.

\section{CONSIDERAÇÕES FINAIS}

Conclui-se que embora nos currículos oficiais aprovados para a Educação básica (Ensino Fundamental I e II) a Geodiversidade não seja citada de forma contundente, a mesma pode ser estudada e seus componentes abordados em diversas habilidades de forma diluída. Ressalta-se a timidez da abordagem da Geodiversidade na educação básica o que demonstra a necessidade da academia de buscar possibilidades para este conhecimento do meio abiótico adentre as escolas. Vale 
lembrar também da autonomia docente e flexibilidade dada ao docente de ministrar o conteúdo como achar necessário, portanto, afirma-se a possibilidade de abordagem da Geodiversidade nessas etapas de ensino.

Compreende-se como exitosa a empreitada tecnológica proposta por diversos meios de comunicação e grupos acadêmicos que tiveram como objetivo a divulgação geocientífica, muito embora seja necessário pontuar a gigante disparidade econômica e de acessos dos alunos da educação básica que impossibilitaram a muitos de terem um ensino de qualidade e acesso as mesmas condições, fazendo também desta pandemia um agente de segregação educacional. Ressalta-se as possibilidades de aplicativos supracitados e de um ensino de Geociências cada vez mais integrado à tecnologia para além dos períodos remotos ou híbridos, sendo, portanto, um novo enfrentamento imposto à educação mundial.

Apresenta-se também neste trabalho por meio de interpretações bibliográficas e de gabinete a eficiência da metodologia de Educação patrimonial e Ambiental para o ensino de Geodiversidade na Educação básica embora pouco a academia tenha refletido sobre a temática na área de educação.

\section{REFERÊNCIAS}

AUSUBEL, D. P. Aquisição e retenção de conhecimentos: Uma perspectiva cognitiva. Lisboa. Editora Plátano, 2003. 35p.

BEZERRA, M. "Patrimônio e Educação Patrimonial". In: CARVALHO, A.; MENEGUELLO, C. (Org.). Dicionário Temático de Patrimônio. Debates contemporâneos. Campinas: Ed. Unicamp, 2020.

BRILHA, J. Património geológico e geoconservação: a conservação da natureza na sua vertente geológica. Braga: Palimage Editores, 2005. 190p.

FRIGÉRIO, R. C. Oficinas Pedagógicas de Geografia: Costurando narrativas de experiência da vida docente. 2018. 213 f. Tese (Doutorado em Geografia) - Instituto de Geociências, Universidade Estadual de Campinas, Campinas, 2018.

GRAY, M. Geodiversity: valuing and conserving abiotic nature. 2. ed. Chichester: John Wiley \& Sons, 2013. 508p.

GRUNBERG, E. Manual de atividades práticas de educação patrimonial. Brasília: IPHAN, 2007. 26p.

ELAZARI, J. M.; HORTA, M. L. P.; GRUNBERG, E.; MONTEIRO, A. Q. Guia básico de educação patrimonial. Brasília: IPHAN: Museu Imperial, 1999. Rev. do Museu de Arqueologia e Etnologia, São Paulo, v. 8, p. 292-193, 1999.

JORGE, M. C. O.; GUERRA, A. J. T. Geodiversidade, Geoturismo e Geoconservação: Conceitos, Teorias e Métodos. Espaço Aberto, Rio de Janeiro, v. 6, n. 1, p. 151-174, 2016. 
HORTA, M. L. P.; GRUNBERG, E.; MONTEIRO, A. Q. Guia Básico de Educação Patrimonial. Brasília: IPHAN, 1999. 65p.

HOSE, T. A. 3G's for modern geotourism. Geoheritage, v. 4, n. 1-2, p. 7-24, 2011.

MANSUR, K. L. Projetos Educacionais para a Popularização das Geociências e para a Geoconservação. Revista do Instituto de Geociências, São Paulo, v. 5, p. 63-74, 2009.

MANSUR, K. L; PONCIANO, L. C. O.; CASTRO, A. R. S. F.; CARVALHO, I. S. Conservação e restauro do patrimônio geológico e sua relevância para a geoconservação. Boletin Paranaense de Geociências, Curitiba, v. 70, n. 9/272, p. 137-155, 2013.

MANSUR, K. L. Patrimônio geológico, geoturismo e geoconservação: uma abordagem da geodiversidade pela vertente geológica. In: GUERRA, A. J. T.; JORGE, M. C. O. (Orgs.). Geoturismo, Geodiversidade Geoconservação: abordagens geográficas e geológicas. São Paulo: Oficina de Textos, 2018.

MAGALHÃES, L. H.; ZANON, E.; BRANCO. P. M. C. Educação Patrimonial: da teoria à prática. Londrina: Ed. Unifil, 2009. 108p.

MEIRA, S. A.; MORAIS, J. O. Os conceitos de Geodiversidade, Patrimônio Geológico e Geoconservação: abordagens sobre o papel da geografia no estudo da temática. Boletim de Geografia, v. 34, n. 3, p. 129, 2017.

MOREIRA, J. C. Geoturismo e interpretação ambiental. Ponta Grossa: Ed. UEPG, 2011, 157p. NASCIMENTO, M. A. L.; RUCHKYS, U.; MANTESSO-NETO, V. Geodiversidade, geoconservação e geoturismo: trinômio importante para a proteção do patrimônio geológico. São Paulo: SBGeo, 2008. 82p.

PONTE, M. L.; PIRANHA, J. M. Ciências da terra no currículo do Estado de São Paulo. Terrae Didatica, Campinas, v. 16, p. 1-13, 2020.

QUEIROZ, E. D.; QUINTALINHA, L. S. As Unidades de Conservação e os riscos: o papel da Educação Ambiental para a comunidade do entorno. In. CARDOSO, C.; SILVA. M. S.; GUERRA, A. J. T. (Org). Geografia e os riscos socioambientais. Rio de Janeiro: Bertrand Brasil, 2020. p. 132152.

SANTOS, L. G.; PACHECO, I. A. Oficina de educação patrimonial para o ensino fundamental em Aquidauana, MS. Revista do Museu de Arqueohgia e Etnologia, São Paulo, v. 8, p. 149-153, 2009.

SILVA, D. G. O ensino de geociências no contraturno escolar decifrando a terra: possibilidades e desafios para inserção das geociências na escola. 2018. 250 f. Dissertação (Mestrado em Geociências) - Instituto de Geociências, Universidade Estadual de Campinas, Campinas, 2018. 